\title{
Effect of Low Voltage AC Fields on Cardiovascular Implants
}

\author{
Anjana Kothandaraman *, Tony Anson and Alan Reynolds
}

Brunel University, Kingston Lane, Uxbridge, Middlesex UB8 3PH

* Corresponding author: Email: anjana.kothandaraman.13@ucl.ac.uk. Present Address:

Department of Mechanical Engineering, University College London, Torrington Place, London, WC1E 7JE, UK

Coronary Artery Stents have been the preferred form of treatment for vascular occlusive disease, due to the minimally invasive surgical procedure, post-operative recovery time and cost, when compared to open coronary bypass surgery. The cellular response upon applying an AC electric field to type 316LM Stainless Steel stent mimics was investigated in this paper. The highest RBC adhesion was observed at voltages higher than $88 \mathrm{mV}$ and lower than $74 \mathrm{mV}$. Their unique alignment along the lines of fracture on the stent surface at $88 \mathrm{mV}$ was a phenomenon caused by an increase in electrical conductivity in these regions. Being able to control RBC adhesion may have various clinical implications such as inhibition of thrombus formation, and provide a basis to analyse whether electric fields may be applied to cancer therapy as well. 


\section{Introduction}

Stents are tiny mesh-like tubular structures that have undergone a lot of structural and material development over the years to evolve into the optimum design. Johnson \& Johnson developed the first FDA approved Bare Metal Stent(BMS) called PALMAZ-SCHATZ balloon expandable stent in 1994[1]. However, BMS were associated with restenosis as identified by Hou et al.[2] in their research. Using optical coherence tomography (OCT), they discovered that after a period of time, new plaque like tissue began to develop inside the bare metal stent implanted in the patient.

The year 2003 marked the new era of stents, Johnson \& Johnson released the first Drug Eluting Stent (DES) into the medical market[1]. It is based on the basic structure of a BMS but it is coated with a dissolvable polymer containing an immunosuppressant drug. Tung et al. [3] made a critical examination of the evidence obtained upon testing a number of patients postoperatively after implantation of a DES. It was observed that restenosis was drastically reduced, but after a period of 9-12 months, thrombus formation was recorded in the patients known as Late Stent Thrombosis (LST). This is because drugs such as Sirolimus and Paclitaxel delay the healing process at the site where the stent was implanted. A consensus was reached that LST is a rare condition, however a potentially fatal one [3]. Therefore it may be necessary for the patient to be administered anti-coagulants drugs for a longer period of time in comparison with a patient with a BMS implant.

Endothelial cells play a vital role in vessel wall repair, thus modification of BMS and DES has been investigated by various researchers $[4,5,6,7]$. Nakazawa et al.[4] emphasized that the stent must maintain sustained inhibition of smooth muscle cell proliferation whilst promoting endothelial cell coverage along the stent surface, thus the concept of re-endothelialization of 
the stent became an essential factor to promote integration of the device with the vascular structure.

A novel method to optimise this behaviour would be to modify the substrate without the use of further drugs/medication. Szmitko et al. [8] argued that prior harvesting of endothelial cells on the prosthetic conduit is labour intensive and time consuming, furthermore it may cause distortion of the cell phenotype[8]. Zhao et al. [9] derived a theory that electrical stimulation directly induces angiogenic responses that promotes enhanced production of Vascular Endothelial Growth Factors (VEGF). This is because cells are enclosed by a cell membrane which consists of an ionic solution. Typically, voltage values outside and inside the cell varies and is measured in millivolts $(\mathrm{mV})$ [10]. He et al. [11] indicated that the membrane potential modulates calcium influx and calcium-dependent endothelial functions, however there may be more than one ion channel, therefore currents flow across both channels until a steady state/equilibrium is reached[12]; this is known as the Resting Membrane Potential of the cell. In this work, an AC electric field was applied to 316 Stainless Steel stent mimics and the normal circulation of blood was simulated using an experimental set-up with Ovine blood for 2 hours. The stents were fixed using glutaraldehyde solution and examined using Scanning Electron Microscopy (SEM) to evaluate cell behaviour. 


\section{Materials and Methods}

\subsection{Materials}

The set-up is composed of a main blood tank which holds $2 \mathrm{~L}$ of whole ovine (Sheep) blood (Reference Number SBO55, Sheep Defibrinated Blood 500ml, TCS Biosciences Ltd.) A silicone pipe from the main blood tank leads to a 10-way manifold shown in figure 1 . The 10 -way manifold distributes blood through 10 silicone tubes, representing the coronary arteries(figure 2a). Silicone was chosen for the tubing due to the number of useful physical and biocompatibility properties of the material. It displays excellent thermal and electrical properties. The advantage of this characteristic is that the loss of heat from the blood flowing through the tubes by convection and conduction will be minimised. In addition, the elastic properties of silicon approximate a blood carrying vessel.

An electric water bath (TechneTempette TE-8A) maintained the blood temperature at $37^{\circ} \mathrm{C}$ $\pm 1^{\circ} \mathrm{C}$ using a heat exchanger. A peristaltic pump generates sufficient pressure to return blood to the hydrostatic overhead tank, facilitating a sealed and closed-loop recirculation system.

\subsection{Stent Preparation}

Stent mimics were created using $10 \mathrm{~mm}$ long tubes (internal diameter=3mm) of type 316LM Stainless Steel, which is essentially an alloy of chromium and iron reinforced by addition of Molybdenum and Nickel to enhance its mechanical properties. A $1 \mathrm{~mm}$ hole was drilled into the stainless steel structure, through which a wire is passed through to affect an electrical connection. A vertical slit of $0.6 \mathrm{~mm}$ depth was milled through into the stent wall to ensure that the stent could be easily opened to investigate the luminal surfaces prior to SEM analysis (figure $2 \mathrm{~b}$ ). Once washed with ethanol to remove any grit/dirt, they were placed in 
the lumen of the silicone tubes, with a pig-tail electrical connection, as shown in figure $2 \mathrm{c} .9$ Stent mimics were polarised with voltages ranging from $65 \mathrm{mV}-111 \mathrm{mV}$. The remaining stent, identical in all respects, was the control sample, but without an electrical potential. They were finally mounted serially onto a 10 -way manifold as shown in figure 2 a to maintain mechanical stability.

\subsection{Stabilisation of Temperature and Pressure}

The setting on the water bath was finally established to be $48^{\circ} \mathrm{C}$ to overcome any heat lost producing a temperature reading of $37^{\circ} \mathrm{C}$ in the Blood reservoir. Convection, conduction and radiation account for the $9^{\circ} \mathrm{C}$ temperature loss. The pressure of the flow from the main tank towards the manifold was measured using a mercury manometer. The pressure was recorded to be $130 / 80(135 \mathrm{~mm} / \mathrm{Hg})$, this pressure was achieved by ensuring that the height between the centre of the experimental stent array to the centre of the hydrostatic tank outlet port was $1.64 \mathrm{~m}$. The flow rate of the pump is constrained by the calibre of pump, energy shedding, due to visco-elastic pressure drop in the $3.5 \mathrm{~mm}$ silicone tube.

\subsection{Electrical Set-Up}

10 potentiometers were soldered on to a Veroboard as shown in figure $3 a$. A connection was made from each potentiometer to 9 wired stents to obtain various voltages. The veroboard was connected to a sweep function generator which outputs an A.C field. The resistance was altered in order to vary the voltage generated as shown in the circuit diagram in figure $3 b$. 


\subsection{Analysis}

$2 \mathrm{~L}$ of Ovine blood was circulated through the pipe-work for a total of 2 hours once the temperature of the blood reached $37^{\circ} \mathrm{C}$. The Stents mimics were placedGlutaraldehydefixative $+\mathrm{PO}_{4}$ buffer for 2 hours. They were then washed twice each in a phosphate buffer which composed of $1 \mathrm{~L}$ of Sodium dihydrogen orthophosphate dihydrate and $1 \mathrm{~L}$ of di-sodium hydrogen orthophosphate dodecahydrate in order to maintain $\mathrm{pH}$ stability. They were rinsed with distilled/de-ionised water for 15 minutes each. The samples were then dehydrated with $30 \%, 50 \%, 70 \%$, and $90 \%$ of ethanol each and finally $100 \%$ ethanol twice. They were dried to critical point using a critical point drying machine, then coated with $15-20 \mathrm{~nm}$ of gold using a sputter coater which were then analysed using Scanning Electron Microscopy (SEM).

\section{Results and Discussion}

Polarising the stents with different voltages ranging between $65 \mathrm{mV}-111 \mathrm{mV}$ did not yield endothelial cells upon SEM analysis, however displayed very interesting results. Based on the findings, it appears that various A.C voltages have very different effects on the Red Blood Cell adhesion. A large thrombus formation was observed in the control sample (figure 4a). This could be due to hemolysis, as the geometry of the stainless steel stent mimics used in the experiment was not engineered to reduce shear forces. As the inner surface was not bead blasted, there were many fractures on the inner surface contributing to an overall uneven surface architecture.

Looking at the sample polarised by $111 \mathrm{mV}$ (figure $4 \mathrm{~b}$ ), strands of fibrin are present. These are marked by the red arrows. Presence of fibrin polymeric strands is a strong indication of the coagulation process. Fibrin is responsible for maintaining the mechanical stability of 
blood clots, it renders the clot stable and prevents its break down. This natural biological process occurs to prevent a haemorrhage occurring every time a capillary is injured, or a small laceration is made on the skin. Platelets are an essential component in the blood stream, they aid in preventing blood loss by aggregating cells to form a blood clot[13]. When these platelets are activated, they have the capacity to alter their shape and structure and stick together; this dense cluster is held by fibrin strands. The highest and lowest voltages tested have shown to adhere an abundant proportion of cells (figures $4 b$ and $h$ ). Large numbers of RBC bound by fibrin strands were present in the stent polarised by $102 \mathrm{mV}$ as shown in figure 4c.; this phenomenon was present in the sample polarised $94 \mathrm{mV}$ as well. From figure $4 d$, the RBC appear to be collapsed; this could be due to insufficient fixation of the sample.

Analysing the samples which polarised using the mid-range voltages, it can be observed that the density differs from the previously discussed results. When the sample was polarised by $80 \mathrm{mV}$, the density of RBC was greatly reduced, (figure $4 \mathrm{f}$ ) the red blood cell distribution is very dispersed and isolated.

Interestingly, reducing the voltage further to $74 \mathrm{mV}$ (figure $4 \mathrm{~g}$ ) increased the RBC adhesion on the substrate. Further reducing the applied potential difference to $65 \mathrm{mV}$ resulted in the aggregation of RBC along the stent surface as shown in figure 4h.Looking at the trend displayed by samples, it can be seen that voltages greater than $74 \mathrm{mV}$ but lower than $88 \mathrm{mV}$ reduced RBC adhesion; this property can potentially be used to reduce thrombus formation in the stent. An interesting test would be to analyse the behaviour of RBC with voltages ranging from $81 \mathrm{mV}-73 \mathrm{mV}$ to derive an understanding as to below which voltage causes an increase in RBC adhesion. 
Increasing the voltage to $88 \mathrm{mV}$ produced very intriguing results. From figure $4 \mathrm{e}$, it can be seen that the cells form a very distinct pattern on the surface of the substrate. Cells appear to be arranged in lines. The red arrow indicates a fracture on the surface of the substrate; a series of cells have adhered along the fracture line indicated by the blue bracket. This behaviour was noticed in other samples where fractures on the surface were present(figure4f). A possible explanation can be developed with regard to the oxide layer formed when the chromium component reacts with the oxygen in the blood and air. The oxide formed is chromium oxide which is a ceramic, thus more susceptible to fracture due to its weaker mechanical properties. Scratches formed due to fracture on the surface expose the metal underneath the oxide layer to the electric field; thereby could potentially increase the electrical conductivity of these areas, hence promoting RBC adhesion with these distinctive patterns.

It is essential to evaluate the possible reasons why the results did not yield any endothelial cells. Alternating Current consists of a positive half cycle is and a negative half cycle. The voltage is continuously switching from negative to positive; this could cause confusion amongst the cells. As explained in depth in the review, cells have a negative membrane potential, therefore would be attracted to a positive voltage. The period of time where the cycle is positive may not have been sufficient to attract these endothelial cells, however it affects the behaviour of red blood cells. This discovery could have potential clinical benefits as it could be used to control RBC adhesion on implants. It can potentially reduce accumulation of red blood cells/blood clots. Myocardial infarction occurs when clot travels along the blood stream as an embolus blocking the blood flow to various vital tissues. 
Coagulation in other circumstances may be advantageous; an example would be in the treatment of cerebral aneurysms. Intracranial aneurysms require immediate medical attention as they are highly prone to rupture. Rupture will result in bleeding of the cranial arteries; when this occurs, the tissues in the brain fail to receive adequate oxygen supply, resulting in hemorrhagic stroke [14], furthermore causing a build of pressure and swelling amongst surrounding cranial tissue. Pressure may induce compression of the brain tissue which leads to coma and unconsciousness [16].

Current form of treatment involves using an endovascular wire $[14,15]$, which is transported along the femoral artery towards the brain using a catheter. This wire is then coiled up inside the aneurysm to take the shape of the structure; commonly used materials for the coil are platinum [14] due to its radiopacity and more recently, shape memory alloys such as nitinol. This coil causes disruption of the blood flow, which initiates the process of coagulation, which essentially acts as plug preventing rupture of the aneurysm. This process could be reinforced by applying a particular AC current which could promote the RBC adhesion, therefore improving the overall coagulation process.

The finding regarding the effects of electric fields on cells can potentially be applied to cancer therapy. Several theories correlating cancerous cells to depolarised voltage membrane potential (Vmem) values have been discussed in the literature $[17,18]$. Typical membrane potential values for healthy tissue range between $-10 m V$ to $-90 m V$ as shown in figure $5[17,18,19]$. It can be seen that tumour cells and certain non-tumour cells such as proliferating fibroblasts and 3T3 cells possess lower membrane potential values; hence further research has suggested that ion channels/transporters such as $\mathrm{Na}+, \mathrm{Ca} 2+, \mathrm{K}+$, and $\mathrm{Cl}-$ (Sodium Ion, Calcium Ion, Potassium ion and Chlorine ion respectively) are contributing 
factors to cancer progression. $\mathrm{Na}+$ is responsible for the depolarisation phase of action potentials in excitable cells such as neurons and smooth muscle cells[20]. Sodium and Chlorine ions have been reported to be at elevated levels in tumour cells [21], which results in their lower polarity values. Several methods of quantifying ion levels have been reported over the years[20-22], more recent methods include electrophoresis[22]. Hence, altering ion channel activity can regulate the voltage membrane potential to promote normal cell differentiation and cell activity. A possible way to mediate this process would be to insert a probe to the affected area to measure the ion concentrations, and depending on the values extracted, administer possible drugs to increase/decrease the relative concentration of the ion. Inducing an AC electric field at the affected region could possibly facilitate the adherence of the drugs and promote cell stability, working in a similar manner to targeted drug delivery. However these theories would require further investigation to understand the range of $A C$ voltages that influence ion migration. Potential benefits of exploiting electric field treatment include minimising the use of radiation, which has the tendency prolong the patients' transit in the hospital and affecting their normal life style significantly. Since the range of voltages used would be low, cellular damage could be minimised.

\section{Present Standing and Future work}

Understanding that electric fields influence cell behaviour can potentially be incorporated into current research on cardiovascular biomaterial surfaces [23,24]. Recent studies have focused on coating the substrate surfaces using molecules prevalent in the Extra Cellular Matrix (ECM) such as Fibronectins, Laminin and Collagen [23]. These are molecules that promote Endothelial Cell proliferation; therefore coating the substrate evenly is vital. Investigating the range of voltages that display maximum adherence of the coating could be 
a possible method to merge the theories derived from the experiments described in this communication with the concept of surface coatings. Fusing nanotechnology with cardiovascular stent design is another strategy reported in recent literature [24], to facilitate the spreading and distribution of cells on the device surface. Introducing nanoparticles on the stent surface extends the functionality of the stent by sustained drug delivery at the site of implantation. Being able to modify the device surface in various ways enables growth of healthy cells along the substrate, thus integrating the device with the body and limiting Foreign Body Response and device rejection.

\section{Conclusion}

This work was initially aimed at potentially attracting endothelial cells, with the intention of creating a film of cells on the stent. It was observed that there were no endothelial cells present in the samples examined. Results indicated that different AC voltages had varied effects on RBC adherence. Controlling the RBC density deposited on the substrate can potentially demonstrate clinical benefits. However, these theories require further research and investigation to develop a better understanding of the implications of RBC adherence in with a practical/clinical perspective.

\section{Acknowledgements}

The corresponding author would like to sincerely thank Professor Mohan Edirisinghe from the Mechanical Engineering Department, University College London for facilitating the development of this communication. 


\section{References}

[1] JAVAID., I., JULIAN., G. \& PATRICK., S. 2013. Coronary stents: historical development, current status and future directions British Medical Bulletin, 106, 193-211.

[2] HOU, J., QI, H., ZHANG, M., MA, L., LIU, H., HAN, Z., MENG, L., YANG, S., ZHANG, S., YU, B. \& JANG, I. K. 2010. Development of lipid-rich plaque inside bare metal stent: possible mechanism of late stent thrombosis? An optical coherence tomography study. Heart, 96, 1187-90.

[3] TUNG, R., KAUL, S., DIAMOND, G. A. \& SHAH, P. K. 2006. Narrative Review: Drug-Eluting Stents for the Management of Restenosis: A Critical Appraisal of the Evidence. Annals of Internal Medicine, 144, 913-919.

[4] NAKAZAWA, G., GRANADA, J. F., ALVIAR, C. L., TELLEZ, A., KALUZA, G. L., GUILHERMIER, M. Y., PARKER, S., ROWLAND, S. M., KOLODGIE, F. D., LEON, M. B. \& VIRMANI, R. 2010. AntiCD34 antibodies immobilized on the surface of sirolimus-eluting stents enhance stent endothelialization. JACC Cardiovasclnterv, 3, 68-75.

[5] LEE, J. M., CHOE, W., KIM, B. K., SEO, W. W., LIM, W. H., KANG, C. K., KYEONG, S., EOM, K. D., CHO, H. J., KIM, Y. C., HUR, J., YANG, H. M., CHO, H. J., LEE, Y. S. \& KIM, H. S. 2012. Comparison of endothelialization and neointimal formation with stents coated with antibodies against CD34 and vascular endothelial-cadherin. Biomaterials, 33, 8917-27.

[6] YIN, M., YUAN, Y., LIU, C. \& WANG, J. 2009. Combinatorial coating of adhesive polypeptide and anti-CD34 antibody for improved endothelial cell adhesion and proliferation. J Mater Sci Mater Med, 20, 1513-23.

[7] MIGLIONICO, M., PATTI, G., D'AMBROSIO, A. \& DI SCIASCIO, G. 2008. Percutaneous coronary intervention utilizing a new endothelial progenitor cells antibody-coated stent: a prospective single-center registry in high-risk patients. Catheter CardiovascInterv, 71, 600-4.

[8] SZMITKO PE, K. M., STEWART DJ, STRAUSS MH, VERMA S. 2006. Endothelial progenitor cell-coated stents under scrutiny. Canadian Journal Of Cardiology, 22, 1117-1120.

[9] ZHAO M, B. H., WANG E, FORRESTER JV, MCCAIG CV 2003. Electrical stimulation directly induces pre-angiogenic responses in vascular endothelial cells by signalling through VEGF receptors. Journal of Cell Science. Journal of Cell Science, 117, 397-406.

[10]HODGKIN, A. L. \& RUSHTON, W. A. H. 1946. The Electrical Constants of a Crustacean Nerve Fibre. Proceedings of the Royal Society B: Biological Sciences, 133, 444-479.

[11]HE, P. \& CURRY, F. E. 1995. Measurement of Membrane Potential of Endothelial Cells in Single Perfused Microvessels. Microvascular Research, 50, 183-198.

[12]MATTHEW., S., ERIK., B. \& STEVEN., S. 2011. Calcium and Electrical Signalling along Endothelium of the Resistance Vasculature Basic \& Clinical Pharmacology \& Toxicology, 110, 80-86. 
[13] MARGUERIE G.A , P. E. F. A. E. T. E. 1979. Human platelets possess an inducible and saturable receptor specific for fibrinogen. The Journal of Biological Chemistry, 254, 5357-5363.

[14] CROMPTON M.R. 1966. Mechanism of growth and rupture in cerebral berry aneurysms.pd. British Medical Journal, 1, 1138-1142.

[15] WHITE, P. M., LEWIS, S. C., GHOLKAR, A., SELLAR, R. J., NAHSER, H., COGNARD, C., FORRESTER, L. \& WARDLAW, J. M. 2011. Hydrogel-coated coils versus bare platinum coils for the endovascular treatment of intracranial aneurysms (HELPS): a randomised controlled trial. The Lancet, 377, 16551662

[16]KEEP, R. F., HUA, Y. \& XI, G. 2012. Intracerebral haemorrhage: mechanisms of injury and therapeutic targets. The Lancet Neurology, 11, 720-731.

[17] YANG, M., BRACKENBURY, Y.J. 2013. Membrane Potential and Cancer Progression. Frontiers in Physiology, 4, 1-10.

[18] SUNDELACRUZ, S., LEVIN, M., KAPLAN, D.L. 2013. Role of membrane potential in the regulation of cell proliferation and differentiation. Stem Review and Response, 5, 1-10.

[19] BINGGELI, R., WEINSTEIN, R.C. 1986. Membrane potentials and sodium channels: Hypotheses for growth regulation and cancer formation based on changes in sodium channels and gap junctions. Journal of Theoretical Biology, 123, 377-401.

[20] YANG, M., KOZMINSKI, D.J., WOLD, L.A., MODAK R., JEFFREY D.C., L.L, ISOM., BRACKENBURY W.J. 2012. Therapeutic potential for phenytoin targeting Nav1.5 sodium channels to reduce migration and invasion in metastatic breast cancer. Breast Cancer Research and Treatment, 134, 603-615.

[21] SMITH, N.R., SPARKS, R.L., POOL, T.B. 1978. Differences in the intracellular concentration of elements in normal and cancerous liver cells as determined by X-ray microanalysis. Cancer Research, 38, 1952-1959.

[22] DOBRZYNSKA I., SZACHOWICZ-PETELSKA B., SULKOWSKI S., FIGASZEWSKI Z. 2005. Changes in electric charge and phospholipids composition in human colorectal cancer cells. Molecular and Cellular Biochemistry, 276, 113-119.

[23] LIU T., LIU S., ZHANG K., CHEN J., HUANG N. 2014. Endothelialization of implanted cardiovascular biomaterial surfaces: The development from in vitro to in vivo. Journal of Biomedical Material Research Part A. 102A, 3754-3772.

[24] ARSIWALA A., DESAI P., PATRAVALE V. 2014. Recent advances in micro-nanoscale biomedical implants. Journal of Controlled Release. 189, 24-45. 


\section{Figures}

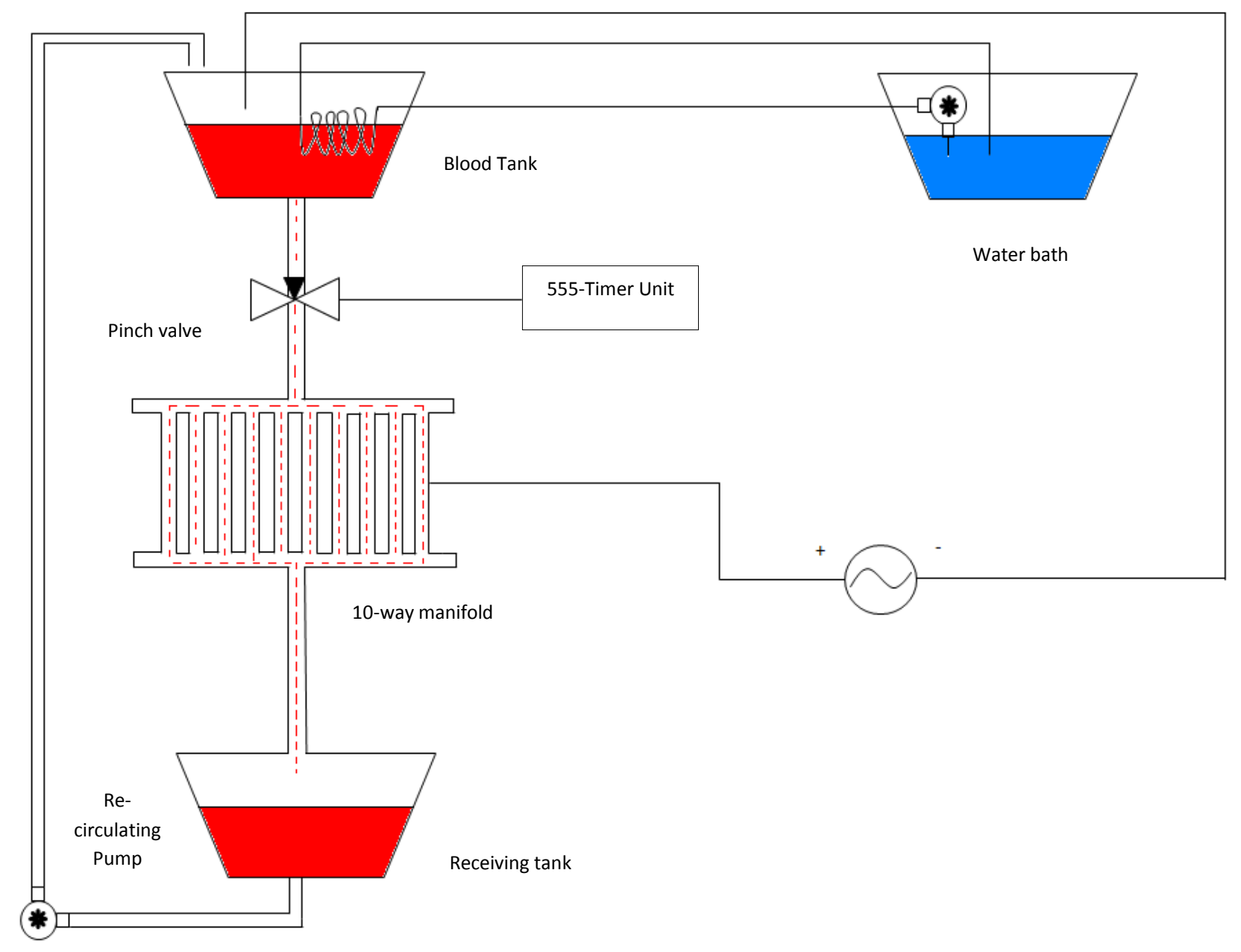

Figure 1: Schematic of overall Experimental Set up 
a)

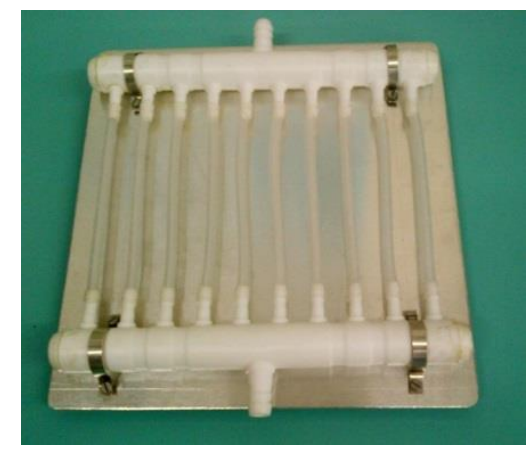

b)

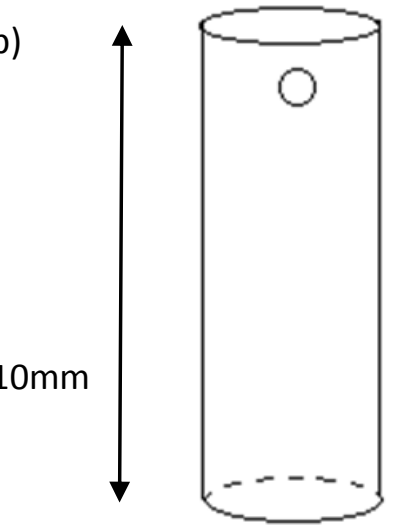

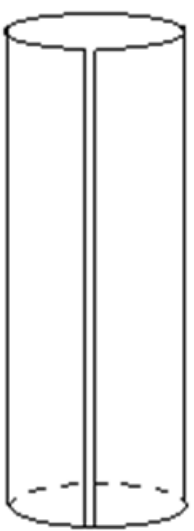

c)

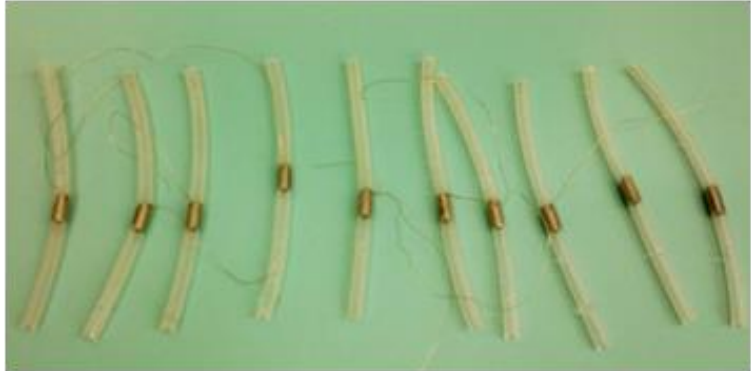

Figure 2: a) 10-way Manifold b) Stainless Steel Tube displaying the hole to pass wire through and cut through the middle to ease the opening of the stent for analysis. c)Stent Mimics Mounted on the Silicone tubes

a)

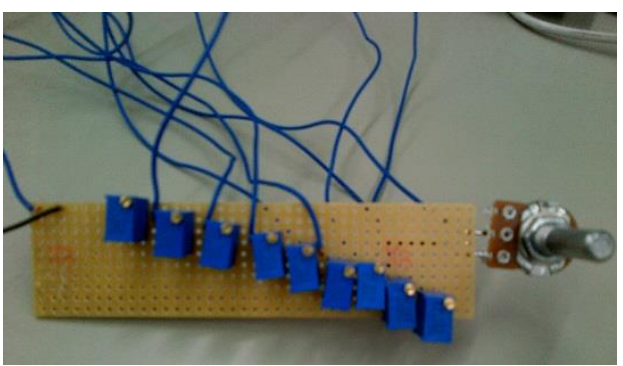

b)

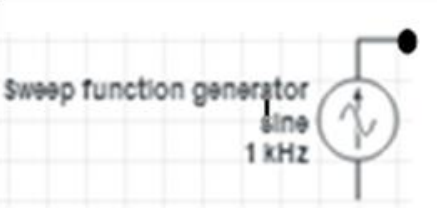

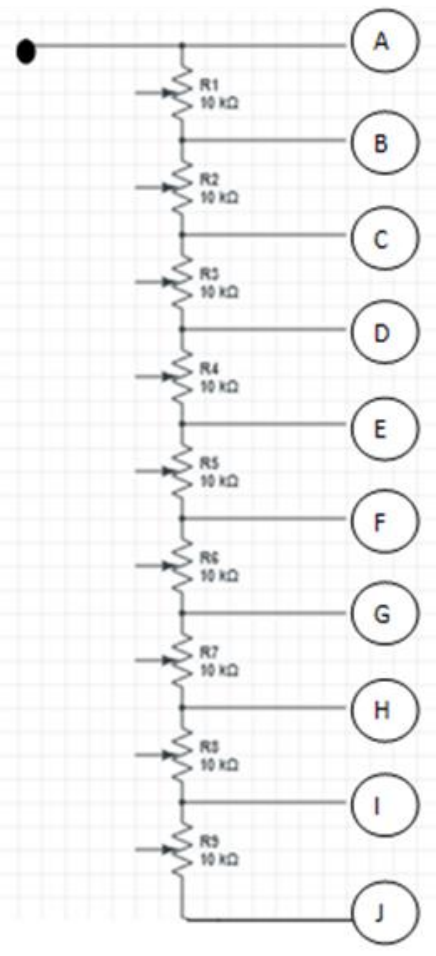

Figure 3: a) Potentiometer Circuit to obtain various voltages b) Corresponding Circuit Diagram, letters indicate specific voltage 
a)

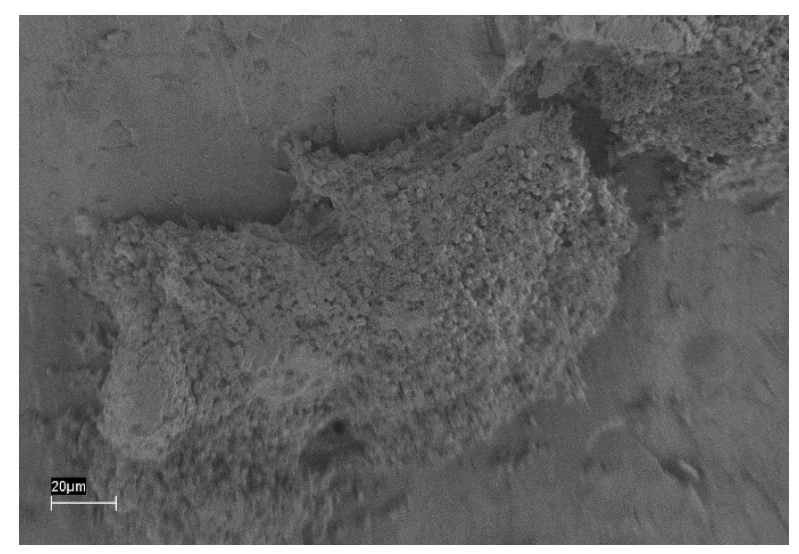

c)

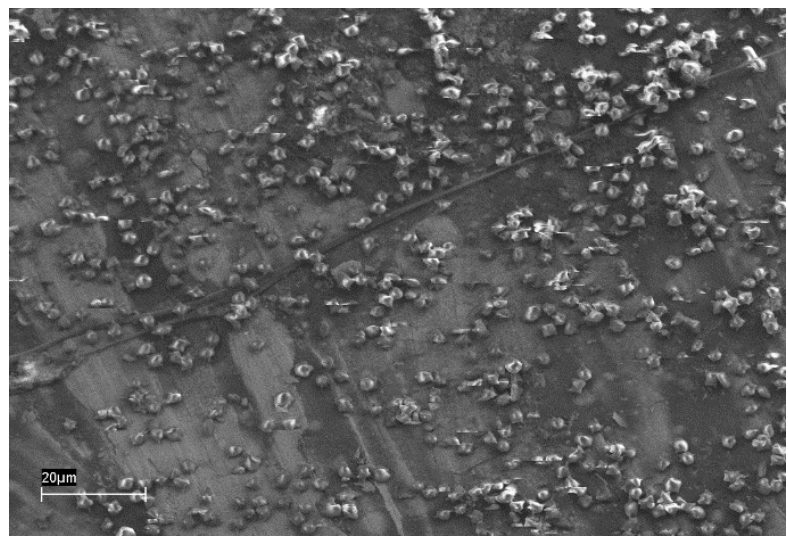

e)

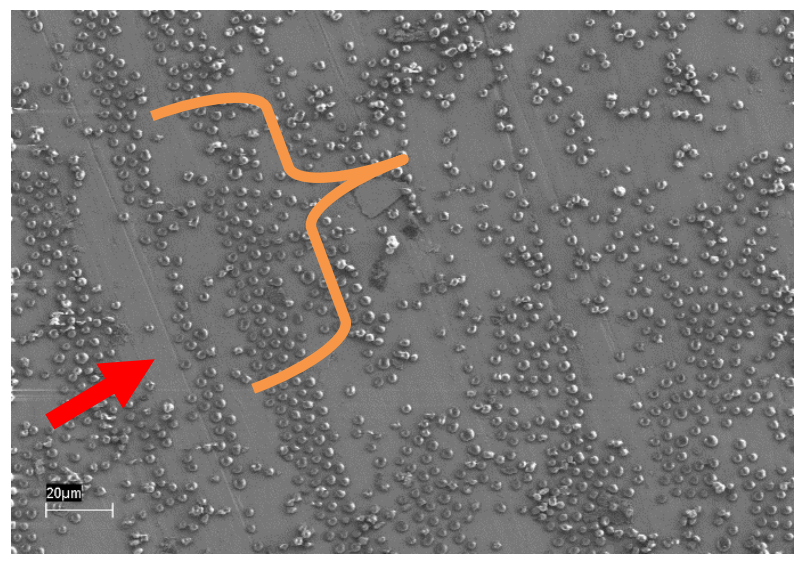

g)

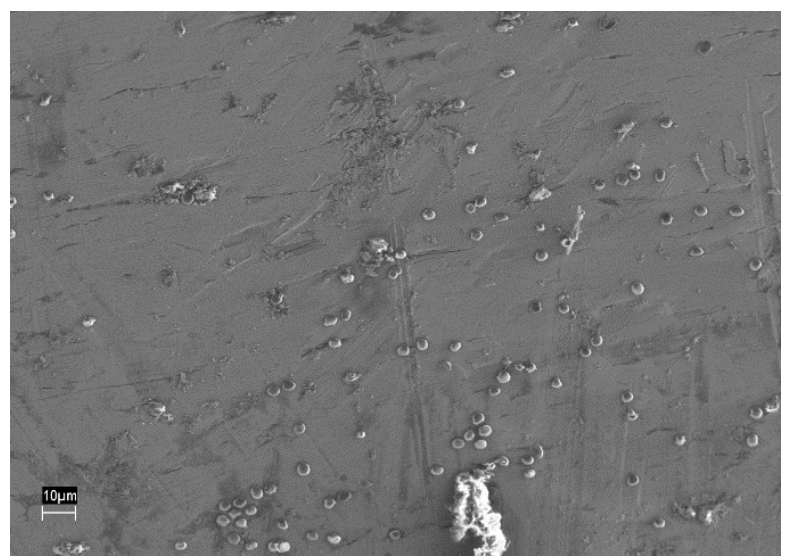

b)

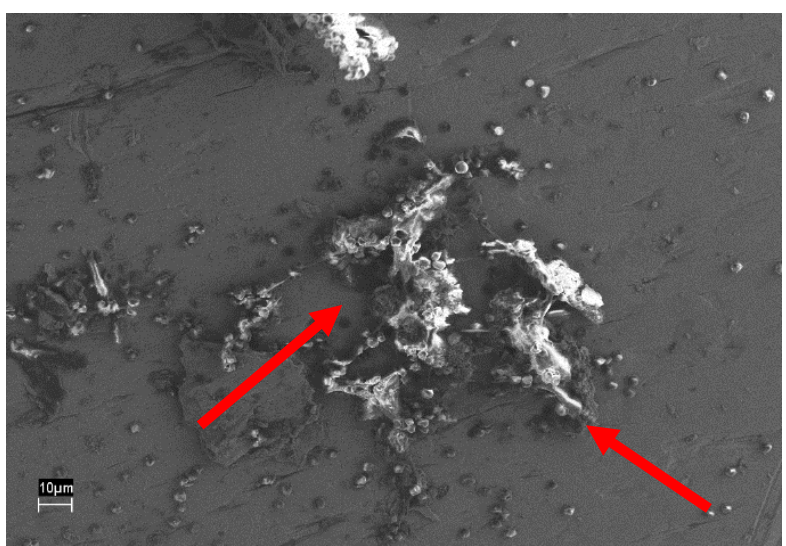

d)

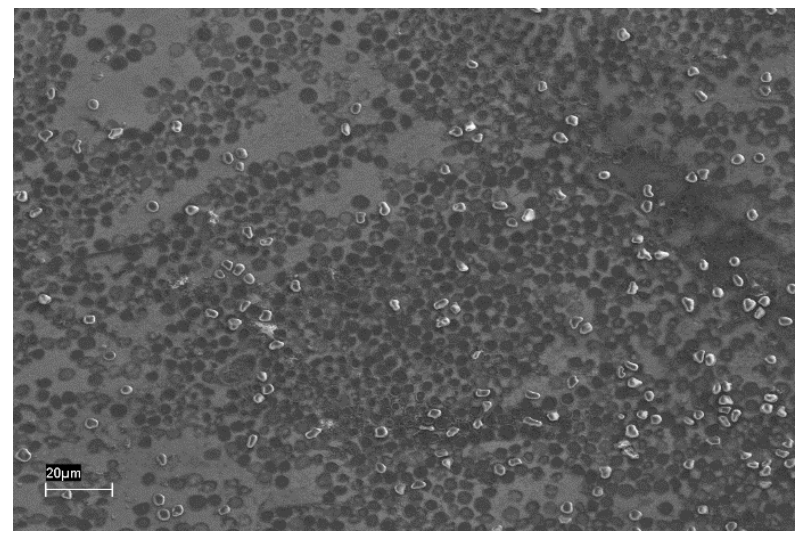

f)

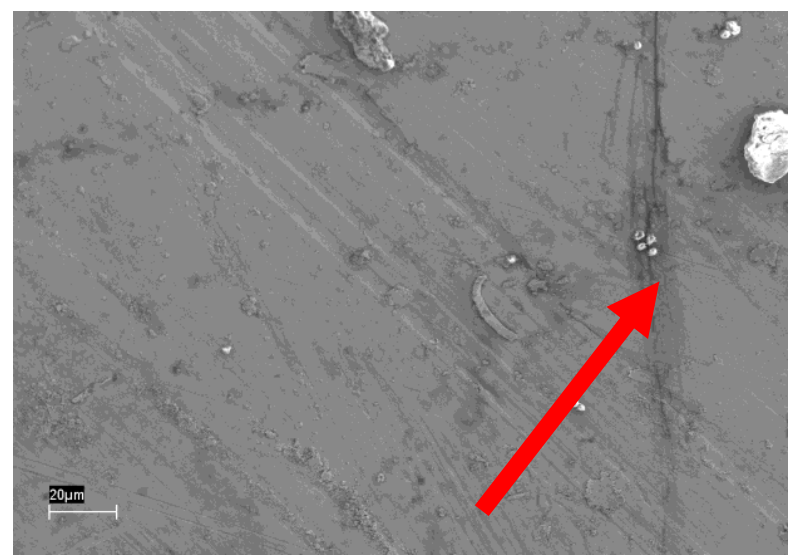

h)

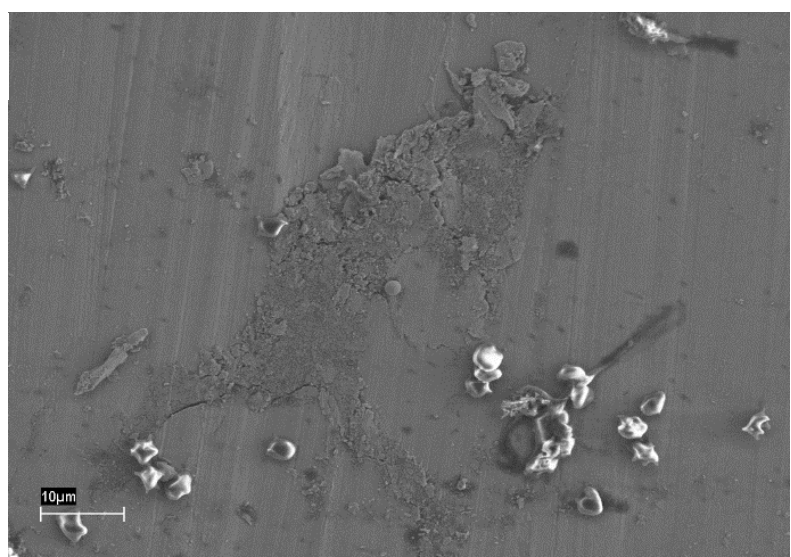

Figure 4: SEM results at different voltages a) Control sample indicating thrombus formation b) $111 \mathrm{mV}$ - arrows indicate strands of fibrin c) $102 \mathrm{mV}$-abundance of RBC on substrate d) $94 \mathrm{mV}-$ indicating collapsed $R B C$ e) $88 \mathrm{mV}$ - distinct patterns on substrate surface f) $80 \mathrm{mV}$ - visible reduction of RBC adhesion, presence of fibrin strand g) $74 \mathrm{mV}$ - increase in RBC adhesion h) $65 \mathrm{mV}$ - Aggregation of RBC on substrate surface. 


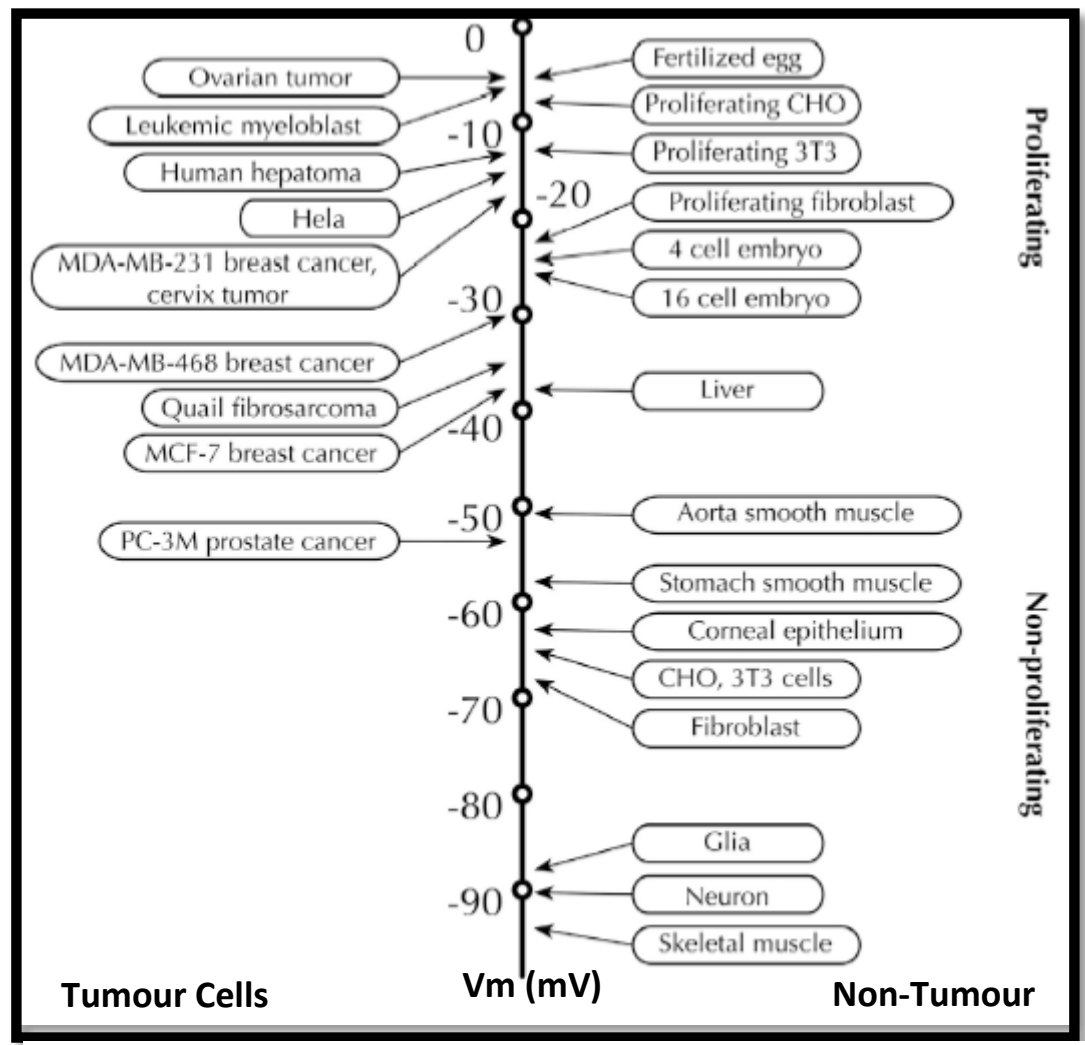

Figure 5: Range of membrane potential values of healthy and tumour cells [adapted from 17-22] in millivolts. 


\section{Dr. Alan Reynolds}

I have worked at Brunel for 35 years, the last 20 as Deputy Director ETC. I am responsible for the running of the Centre and also for teaching, training, research and consultancy services. My own research is in the fields of environmental science, metal uptake by cells and metallic nanoparticle synthesis using green technologies. My academic status is Reader and I am at present a degree moderator/referee for the Chemistry Departments at GC University, Lahore and Hazara University both in Pakistan. At present, I am actively involved in collaborations with Cambridge University, UCL, Sheffield University and The Courtauld Institute.

\section{Prof. Tony Anson}

Professor Tony Anson trained as a mechanical engineer and for the last 30 years has been closely involved in research and development of cardiovascular, orthopaedic and general surgery instruments and devices. Generating ideas to improve clinical outcomes has led to a special interest in the synthetic-to-biological material interface and the dynamic properties of mammalian cells. Several research activities have resulted in the successful commercialisation of implants and surgical instruments through the formation of university spin-out companies, both public and private organisations.

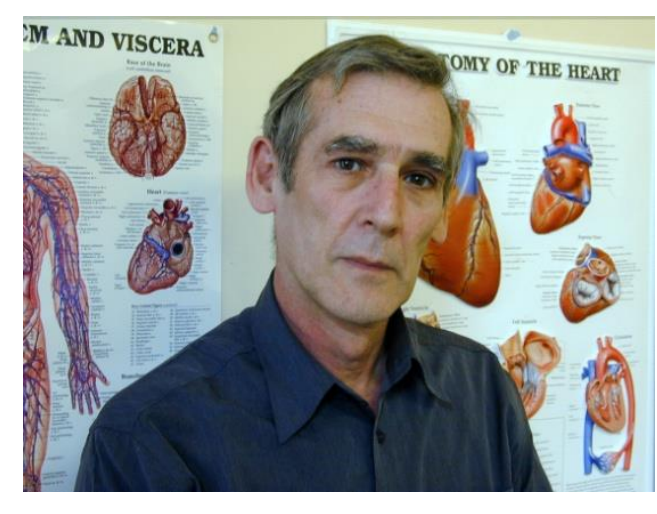

\section{Anjana Kothandaraman}

Anjana Kothandaraman has obtained a BEng with Honours in Computer Systems Engineering and a Masters with Distinction in Biomedical Engineering at Brunel University, West London in 2012 and 2013 respectively. She is currently pursuing her PhD with the department of Mechanical Engineering at $U C L$ in the biomaterials processing and forming laboratory. Her research focuses on combining microfluidic and electrohydrodynamic techniques to generate microbubbles for a wide array of biomedical avenues which will be modelled using computational fluid dynamics (CFD).

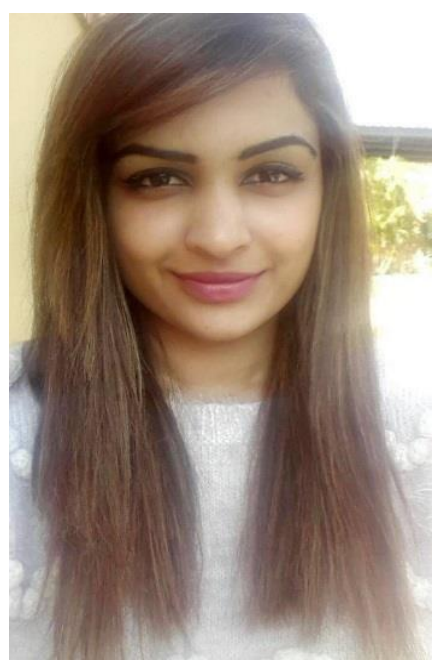

